\title{
Trends in the Installation of Residential Solar Panelsin California
}

\author{
Candace E. Ybarra, John B. Broughton, Prashanth U. Nyer* \\ Argyros School of Business \& Economics, Chapman University, Orange, USA \\ Email: cybarra@chapman.edu,broughto@chapman.edu, „nyer@chapman.edu
}

How to cite this paper: Ybarra, C. E., Broughton, J. B., \& Nyer, P. U. (2021). Trends in the Installation of Residential Solar Panelsin California, 12, 63-72. https://doi.org/10.4236/lce.2021.122004

Received: March 3, 2021

Accepted: June 27, 2021

Published: June 30, 2021

Copyright (C) 2021 by author(s) and Scientific Research Publishing Inc. This work is licensed under the Creative Commons Attribution International License (CC BY 4.0).

http://creativecommons.org/licenses/by/4.0/

\begin{abstract}
This paper examines some trends in residential solar panel installations in California. First, we look at the growth in residential solar panel installations in the state and changes in consumption per account. Next, we examine aspects of the proposed changes to the net metering program in the state. Politicians, the California Public Utilities Commission (CPUC), investor owned utility (IOU) companies and other public interest groups are currently involved in a contentious debate on the future of residential solar panel installations in the state of California. The major California IOUs, Pacific Gas and Electric (PG\&E), Southern California Edison (SCE), San Diego Gas and Electric (SDGE), and others have argued that solar panel installations favor wealthier residential customers at the expense of less wealthy customers. The basis of the argument is that under the current rate structure those with the financial resources to install solar panels are able to avoid paying their share of the fixed costs incurred by utility companies which results in a disproportionate burden on less wealthy customers. IOUs have asked for permission to charge solar customers large additional monthly fees. Some have even called for all the grandfathering protections granted to early solar adopters under the previous and current net metering programs (NEM 1.0 and NEM 2.0) to be withdrawn. Solar companies and residential solar customers have maintained that such moves would destroy the solar industry in the state, cause thousands of job losses, and most importantly, prevent the state from making progress towards its stated carbon neutrality goals. Given this ongoing debate, it is important to examine whether there exists a wealth difference between residential customers in California who have and have not installed solar panels. As an extension of this research, we also went about determining whether climatic conditions impact the solar panel adoption rates. While California is a huge state with varied climatic zones and several utility companies, we focus our analysis on residential customers of SCE who reside in Orange County. The findings and conclusions are generalizable to residential
\end{abstract}


customers throughout the state.

\section{Keywords}

Solar Panels, Net Metering, Wealth, Climate, California

\section{Introduction}

California continues to be at the forefront of the nation in proposing and enacting mandates that are designed to reduce carbon emissions in the future. On September 10, 2018, California Governor Jerry Brown issued executive order B-55-18 to achieve a statewide goal of carbon neutrality no later than 2045 (California Executive Order, 2018). The California Solar Mandate (California Legislative Information, 2019), which went into effect on January 1, 2020, requires new single-family and multi-family residential units up to three stories high to have solar panels that will generate the annual electrical energy needs of those buildings. At the time of this writing, the California Energy Commission is weighing the possibility of crafting new regulations, that could go into effect as early as 2023 , which would severely restrict natural gas connections for new residential constructions or at least incentivize builders to move away from natural gas and instead to rely more heavily on electric options for heating (Roth, 2020). Several cities and counties in the state have already tightened the rules on natural gas, with Berkeley and San Francisco banning natural gas connections in new construction (Morris, 2021). According to the Solar Energy Industries Association (SEIA), these moves have encouraged greater investments in solar projects with approximately 18,000 Mega Watts (MW) of new solar installations made in the state in the five years from 2016 to 2021 (SEIA, 2021), and a cumulative total of approximately $31,900 \mathrm{MW}$, putting the state ahead of all others in the nation. Further, SEIA estimates that approximately $23.5 \%$ of the state's electricity usage is met by solar (SEIA, 2021). While utility-owned solar installations make up most of the solar capacity in the state (approximately 10,000 MW in 2016-2020 according to SEIA), residential solar installations were not far behind (approximately $5000 \mathrm{MW}$ in 2016-2020).

\section{Growth in Residential Solar in California}

The column graph in Figure 1 shows the combined residential solar capacity installed each year for the three major electric utilities in the state (one MW is $1000 \mathrm{~kW})$. These data are drawn from California Distributed Generation Statistics (https://www.californiadgstats.ca.gov/), a database authorized by the California Public Utilities Commission (CPUC). This database contains details of all solar panel installations (including commercial, industrial, educational, military, and residential) in the service areas for the three major investor owned utilities in California (PG\&E, SCE and SDGE). The data being reported in this section of 


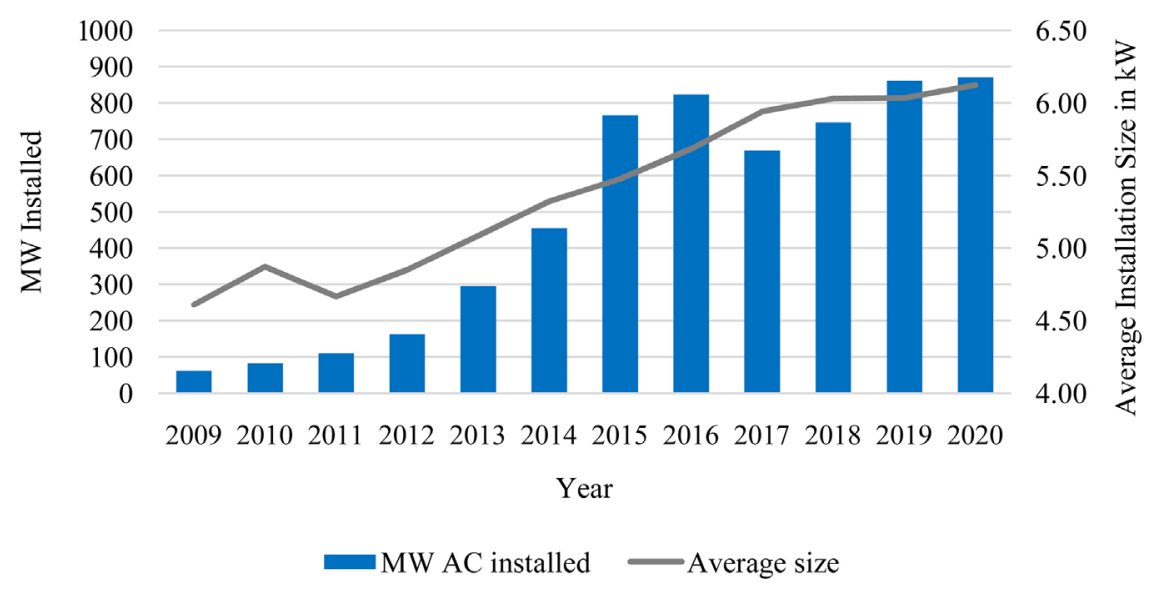

Figure 1. Trends in residential solar installations in California.

the paper pertain to only the residential accounts approved as of December 31, 2020. As the column graph in Figure 1 indicates, there has been a rapid increase in residential solar panel installations in California every year except for 2017. The sharp decline in solar installations from 2016 (824 MW installed capacity across 144,854 installations) to 2017 (669 MW installed capacity across only 112,576 installations) can be attributed to the end of the first implementation of Net Metering (NEM 1.0). Net Metering refers to the tariff structure by which residential solar customers can sell their excess energy generation to the utility company. It is described in detail later in the paper. The impending end of NEM 1.0 undoubtedly caused customers who were considering a solar installation to accelerate the process and install the panels before NEM 1.0 ended (between June 2016 and July 2017 depending on the utility).

The line graph in Figure 1 shows that the average size of solar panel installations has been increasing steadily for the last ten years, which is attributable at least in part to increasing electricity rates in California (see Figure 3 for data on the electricity rates in California). Indeed, the U.S. Energy Information Administration (EIA) estimates that as of March 2021, average electricity rates in California are about $171 \%$ of the US average (US Energy Information Administration, 2021). Higher rates would motivate solar adopters to install solar panel arrays that would offset a larger percentage of their electricity usage. At the same time, the cost of solar panels has fallen, making it more affordable for customers to install larger solar panel arrays.

\section{Reducing Electricity Purchases by Residential Customers}

Several ways to achieve carbon neutrality include reducing energy consumption, developing sources of clean energy, switching to equipment that are more energy efficient, and being mindful of, and reducing, energy wastage. Figure 2 depicts the average annual electricity consumption per household in SCE's service area in Orange County. We restricted our analysis to just one utility and one county to make the analysis easier to perform, but we expect the findings to be applicable 


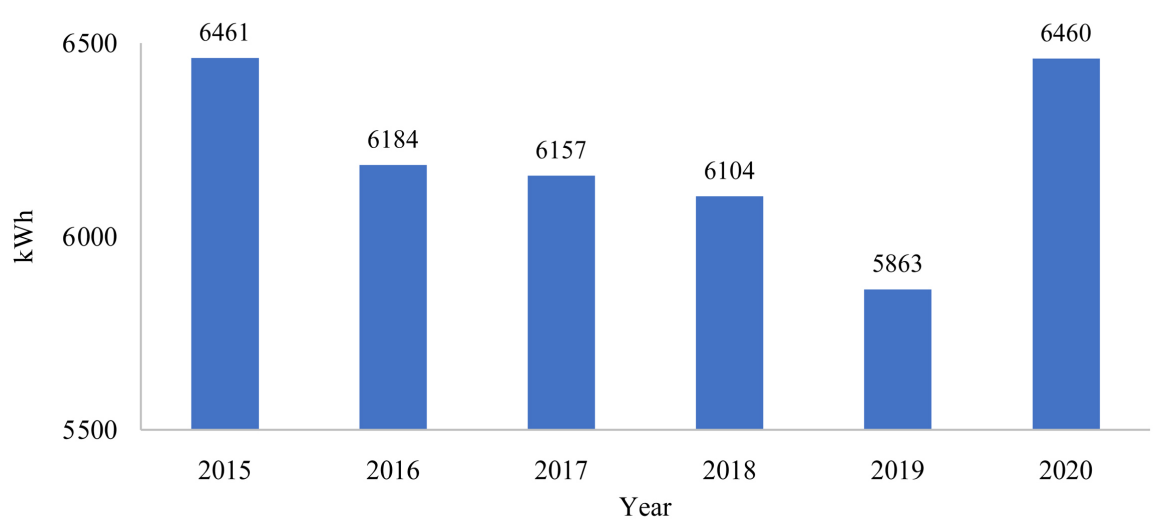

Figure 2. Mean annual electricity purchase per household in Orange County by year.

statewide. Figure 2 uses data from SCE (Southern California Edison, 2021), and shows that the average annual electricity purchase per residential account in kilowatt hours (kWh) has been declining in recent years. At least in part this is due to the switch from incandescent and fluorescent light bulbs to LED bulbs, replacement of older HVAC units with more energy efficient units, greater adoption of solar panels, and a greater awareness of the need for energy conservation. A notable exception to the declining trend occurred in 2020 when the electricity purchase per household increased significantly, undoubtedly because of the increased number of people working and studying from home because of the Coronavirus pandemic. Please note that this figure shows the average annual electricity consumption per household in kWh and not the average annual electricity costs paid by the consumers. A major motivation for reducing electricity consumption is clearly the increasing cost of electricity.

Figure 3 represents data from the EIA (US Energy Information Administration, 2021), and shows that in recent years the average rate paid for electricity by residential customers in California increased far more (39.15\% increase between 2009 and 2020) than the rates paid by residential customers in the country (14.68\% increase for the same time period.) The higher rates being charged for electricity in California could be attributed in part to the stricter regulatory environment in the state, and according to the IOUs, a net metering program that drives up the cost of electricity to compensate for the generous credits offered to the solar customers.

While the data presented thus far would suggest that California is making much progress towards achieving most, if not all, of its carbon neutrality goals, there are significant threats that could derail the residential solar panel business and achievement of the state's carbon neutrality goals.

\section{Upcoming Changes in Net-Metering}

In September 2020, the California Public Utilities Commission (CPUC) began proceedings to determine the future net metering tariffs (usually referred to as NEM 3.0) that are expected to go into effect in 2022 (CPUC, 2020). Net metering refers to the tariff structure by which residential solar customers can sell their 


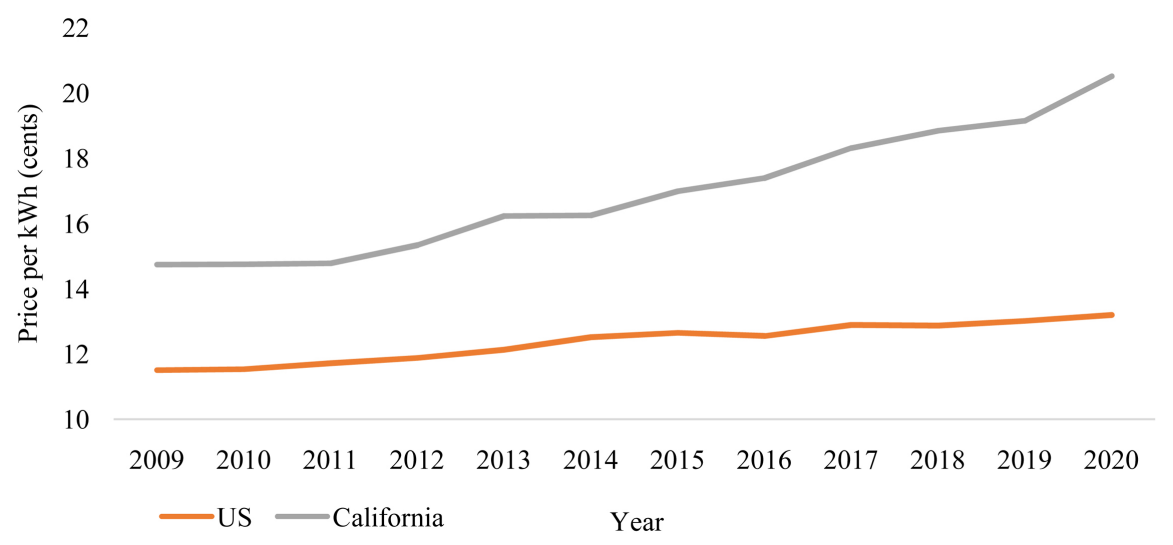

Figure 3. Average price of electricity for residential customers: California vs US average.

excess energy generation to the utility company. The original net metering program (NEM 1.0), which continues to apply to the customers who installed solar arrays while that program was in effect (NEM 1.0 ended between June 2016 and July 2017 depending on which utility company was serving the region) compensates customers for excess energy that they send to the grid at exactly the same rate that the customers pay for energy that they purchase from the grid. The successor net metering program, NEM 2.0, is currently in effect and applies to all customers who went solar after NEM 1.0 ended. NEM 2.0 forces all new solar customers into time-of-use rate plans where the rates for energy are significantly lower during daylight hours, and much higher during peak consumption hours in the evening. Thus, even though the solar customer will be compensated for excess energy generated at the same rate as a non-solar customer will pay for energy purchased during that time slot, the fact that the electricity rates are significantly lower during the peak sunlight hours means that the excess solar generation does not earn as much as with the previous net metering program. In addition, NEM 2.0 included some additional tariffs and fees that were not present in NEM 1.0. Nyer and colleagues showed that despite NEM 2.0 being less financially attractive than NEM 1.0, installing solar panel arrays never the less provides a good return on investment even under NEM 2.0 (Nyer, Ybarra, \& Broughton, 2019; Nyer, Broughton, \& Ybarra, 2019). Customers going solar in 2022 are likely to be on the next net metering tariff, NEM 3.0, which is widely expected to be less attractive to residential solar customers compared to the current NEM 2.0, just as NEM 2.0 was less attractive compared to NEM 1.0.

The IOUs argue that net metering programs favor the wealthy since wealthy consumers have the resources to install solar panels and generate most or all of the energy they consume, and thus pay very little towards the fixed costs (e.g. the cost to maintain the generation and distribution infrastructure) incurred by the IOUs. This, the IOUs argue, results in non-solar customers shouldering most of the fixed costs incurred by the utility companies. The IOUs have proposed a revised tariff structure under which solar customers would be compensated at a much lower rate for excess energy sent to the grid. Further, the IOUs have pro- 
posed that solar customers be charged a hefty monthly grid maintenance fee. A far more drastic proposal has been made by San Diego assembly member Lorena Gonzalez whose Assembly Bill 1139 (AB 1139) would make it financially unviable for customers to go solar AND would eliminate the 20 year grandfathering that early solar adopters had been granted under NEM 1.0 and NEM 2.0 (California Legislative Information, 2021). This bill, if enacted, has the potential to kill the residential solar industry in California.

\section{Are Solar Panels Mostly Installed by Wealthy Residential Customers?}

We now examine the claim that solar panel installations are mostly done by the wealthier customers. As part of investigating that claim we also examine the impact of climatic zones on the adoption of solar panels. The data on the residential solar panel installations for Orange County, California are drawn from California Distributed Generation Statistics, which we described previously. The data being used for the analysis reported in this section of the paper pertain to only the residential accounts serviced by SCE within Orange County, California, and include solar panel installations approved as of October 31, 2020. SCE is the primary electricity service provider for most of the southern California region and it services almost all of Orange County. We decided to confine our analyses to customers from this one compact county to minimize the impact of other extraneous variables.

This dataset provides the size, orientation, tilt, date of commissioning, ZIP code and other items, for each installation in SCE's territory within California. The exact address of each location was not provided in the dataset, and the best measure of location was the ZIP code. Given this, we aggregated the data for each ZIP code area and used the ZIP code areas as our unit of analysis. For each ZIP code we were able to determine the number of SCE customers in each year, the number of customers who had installed solar panels in each year, the average size of the solar panel array, and the average electricity purchased per home.

As Figure 4 (data from California Distributed Generation Statistics, described previously) indicates, the number of residential solar panel installations in the SCE serviced areas of the county have been increasing rapidly and as of October 31,2020 , there were over 51,500 residential solar panel installations in this area totaling over 288 Mega Watt DC capacity. These solar customers accounted for $6.08 \%$ of all SCE residential accounts in this service area.

Our objective is to examine the impact of wealth on the adoption of residential solar panels. It would be reasonable to expect that wealthier homeowners are more likely to install solar panels given that solar panels are not an insignificant investment. As stated previously, our data were aggregated at the level of the ZIP code. We were able to determine the median home value for each ZIP code from Zillow.com which identifies a set of homes in the mid-tier (36 - 65 percentiles) of each zip code and track the value of those homes over time. This avoids the 


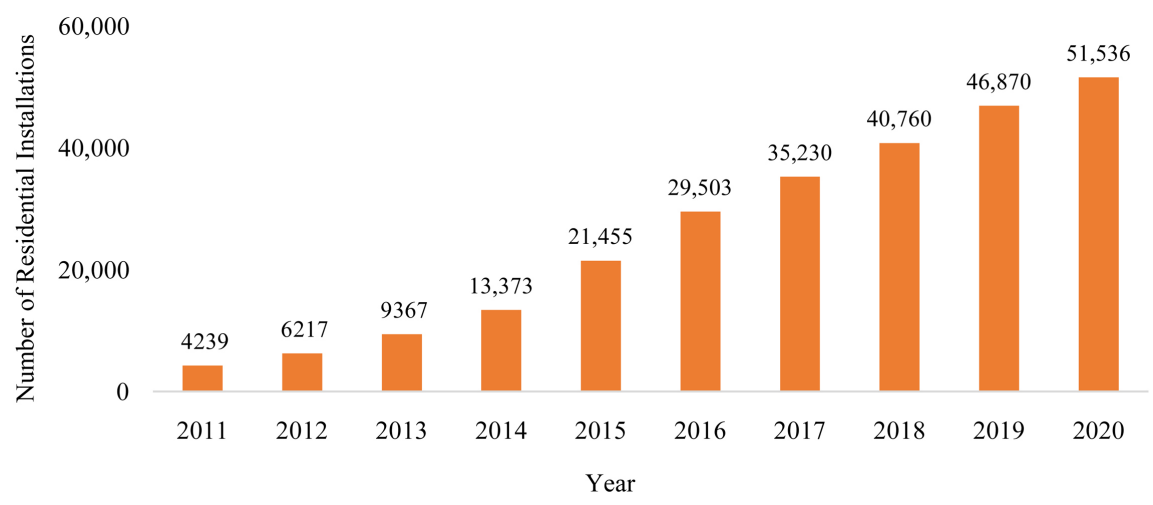

Figure 4. Cumulative residential solar panel installations in Orange County, California.

noise from the median value at any point in time being dependent on the mix of houses that happened to have sold most recently Zillow (2019). We use the median home value as a proxy for the wealth of the homeowners.

Solar adoption rates are influenced not just by the wealth of homeowners but also by the climatic zones in which the homes are situated, with homes in ZIP code areas that experience significantly higher summer temperatures expected to consume more electricity for air-conditioning, and thus being more likely to adopt solar panels. The relationship between high temperatures and electricity consumption is illustrated in Figure 5 where we have plotted the average electricity consumption per residential customer living in ZIP code area 92,867 (a location that is approximately 16 miles from the coast and located in the foothills) for each month in 2020 against the number of hours of temperature above $80^{\circ} \mathrm{F}$ in each month of the same year (TimeandDate.com, 2020). Do note that the secondary vertical axis representing the hours of high temperature has been shifted upwards to better show the relationship between high temperature and electricity consumption. While the data represented here are from one ZIP code area, this relationship between high temperature and electricity consumption is expected to hold in all regions where air-conditioning is used.

To see the true effect of wealth on solar adoption we controlled for climatic zones using the mean monthly high temperature by ZIP code from the National Oceanic and Atmospheric Administration (NOAA) as reported by Google.

The median housing values in Orange County vary greatly by location from below $\$ 600,000$ (parts of Laguna Woods, Santa Ana and Stanton) to over $\$ 3,000,000$ (Newport Beach). We divided the ZIP code areas into 5 pentiles based on median home values with higher category numbers corresponding to higher housing values. Orange County, California has different climatic zones with coastal areas recording relatively lower average monthly high temperatures (for example $71^{\circ} \mathrm{F}$ to $72^{\circ} \mathrm{F}$ in August in Newport Beach) while areas further inland record significantly higher average monthly highs $\left(86^{\circ} \mathrm{F}\right.$ to $87^{\circ} \mathrm{F}$ in August in Brea and Fullerton). We divided the various ZIP code areas in the county into three climate zones, with zone 1 being the areas with the lowest mean monthly highs for the year (below $78^{\circ} \mathrm{F}$ ), zone 3 being the areas with the highest monthly highs 


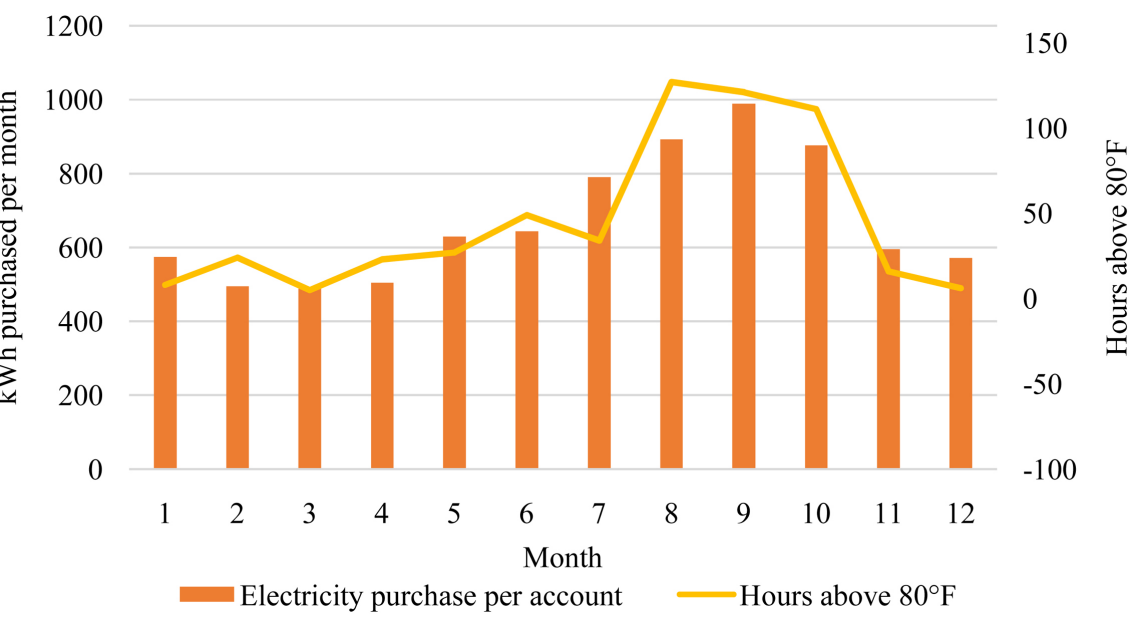

Figure 5. Relationship between high temperature and electricity usage.

(above $85^{\circ} \mathrm{F}$ ) and zone 2 falling in between these extremes. Not surprisingly, the ZIP codes along the coast (where the summer temperatures are the lowest) are also the ZIP codes where the housing values are the highest.

\section{Findings}

Table 1 shows the solar adoption percentage (i.e., the percentage of homes that have installed solar panels) for the various housing value pentiles and climate zones. There are no data corresponding to housing value pentiles 1 to 4 in climate zone 1 (which are ZIP code areas along the coast) since all the ZIP code areas in climate zone 1 have very high median housing values.

To better understand the impact of the climate on solar adoption we could look at the solar panel adoption data for the three climate zones for neighborhoods that fall within the wealthiest ZIP codes (housing value pentile 5). By doing this we can look at the impact of climate zone on solar panel adoption after controlling for housing value (which is a proxy for wealth.) For housing value pentile 5 , the solar adoption rate is strongly associated with the climate zone with the coolest zone showing an adoption rate of $2.85 \%$, increasing to $6.19 \%$ for zone 2 and $9.07 \%$ for the warmest areas of the county.

To examine the impact of wealth (we use housing value as a proxy for wealth) on solar panel adoption we can look at the data for climate zone 3 in Table 1 (thus controlling for climate zone). We see that solar panel adoption increases from $4.38 \%$ for the neighborhoods with the lowest median household value to over $9 \%$ for homes in the two wealthiest housing value categories. Interestingly, the ZIP code areas with the most expensive homes (pentile 5) had an adoption rate $(9.07 \%)$ slightly lower than neighborhoods with slightly less expensive homes (housing value pentile 4 with $9.90 \%$ solar penetration.) The same general pattern holds for climate zone 2. While we do not have any data to support this, we suspect that the very wealthy homeowners in the most expensive neighborhoods are less concerned about their electricity expenses which might be a very small percentage of their monthly expenses. Further, these homeowners may not 
Table 1. Impact of housing value and climate zone on solar adoption.

\begin{tabular}{ccccc}
\hline \multirow{2}{*}{ Housing Value Pentile } & \multicolumn{3}{c}{ Climate Zones } & \multirow{2}{*}{ Total } \\
\cline { 2 - 4 } & 1-Coolest & 2 & 3-Warmest & \\
\hline 1-Least Expensive & - & $2.79 \%$ & $4.38 \%$ & $4.06 \%$ \\
2 & - & $5.17 \%$ & $5.37 \%$ & $5.27 \%$ \\
3 & - & $6.87 \%$ & $8.40 \%$ & $7.64 \%$ \\
4 & - & $5.97 \%$ & $9.90 \%$ & $7.28 \%$ \\
5-Most Expensive & $2.85 \%$ & $6.19 \%$ & $9.07 \%$ & $6.19 \%$ \\
\hline Total & $2.85 \%$ & $5.71 \%$ & $6.75 \%$ & $6.08 \%$ \\
\hline
\end{tabular}

wish to have solar panels on their roofs for aesthetic reasons. In summary, our analysis shows that homeowner wealth is a significant determinant of solar panel adoption with the wealthiest ZIP code areas (in climate zones 2 and 3) having over twice the adoption rate as the least wealthy areas.

\section{Conclusion}

We were able to confirm that the penetration of solar panels was substantially higher in wealthier parts, rather than in the less well-off parts of Orange County, California. This provides some support to the contentions of utility companies and other opponents of residential solar panel installations that residential solar panel installations create a wealth inequity. It also seems logical that concentration of residential solar panel installations among wealthier consumers will lead to their paying smaller electricity bills and contribute relatively less towards the fixed costs incurred by the utility companies. The implication is that a larger portion of the fixed costs would be borne by the non-solar (and less well-off) consumers.

Despite this, implementing some of the proposals that are being suggested to revise the net metering program in California would, in our opinion, greatly diminish the financial attractiveness that solar panel installations present to customers. This, in turn, would slow down the state's progress towards its stated carbon neutrality goals.

\section{Limitations and Future Research}

While the data used in this paper were specific to one IOU in California, the findings should be broadly applicable to all three major IOUs in the state. However, different states have vastly different approaches to residential solar panel installations, and a future study should examine whether the trends in California are reflected elsewhere in the United States. As details of NEM 3.0 get finalized, the economics of residential solar panel installations for the various residential rate plans should be examined to estimate the impact that NEM 3.0 could have on future solar panel installations. One possible means by which solar customers can find savings is by installing battery storage. Future research should extend the work done by Broughton, Nyer and Ybarra (2021) and examine the eco- 
nomics of battery storage when coupled with solar panels, both under the current NEM 2.0 and the future NEM 3.0 programs.

\section{Conflicts of Interest}

The authors declare no conflicts of interest regarding the publication of this paper.

\section{References}

Broughton, J. B., Nyer, P. U., \& Ybarra, C. E. (2021). The Economics of Battery Storage for Residential Solar Customers in Southern California, Forthcoming in American Journal of Industrial and Business Management, 11.

California Executive Order (2018). Executive Order B-55-18 to Achieve Carbon Neutrality. https://www.ca.gov/archive/gov39/wp-content/uploads/2018/09/9.10.18-Executive-Ord er.pdf

California Legislative Information (2019). Assembly Bill No. 178: CHAPTER 259. https://leginfo.legislature.ca.gov/faces/billTextClient.xhtml?bill_id=201920200AB178

California Legislative Information (2021). AB-1139 Net Energy Metering. https://leginfo.legislature.ca.gov/faces/billNavClient.xhtml?bill_id=202120220AB1139

CPUC (2020). Net Energy Metering Rulemaking (R.) 20-08-020. https://www.cpuc.ca.gov/nemrevisit/

Morris, J. D. (2021, January 8). Bay Area Natural Gas Bans Spread in 2020. They're Not Done yet. San Francisco Chronicle.

https://www.sfchronicle.com/business/article/Bay-Area-natural-gas-bans-spread-in-20 20-15854587.php

Nyer, P. U., Broughton, J. B., \& Ybarra, C. E. (2019). The Economics of Residential Solar Panel Installations for Customers on Tiered Rate Plans, Open Journal of Business and Management, 7, 1999-2008. https://doi.org/10.4236/ojbm.2019.74137

Nyer, P. U., Ybarra, C. E., \& Broughton, J. B. (2019). The Economics of Residential Solar Panels: Comparing Tiered and Time of Use Plans. Open Journal of Business and Management, 8, 56-67. https://doi.org/10.4236/ojbm.2020.81004

Roth, S. (2020, December 7). Should California Ban Gas in New Homes? A Climate Battle Heats Up. Los Angeles Times.

https://www.latimes.com/business/story/2020-12-07/should-california-ban-gas-in-new -homes-a-climate-battle-heats-up

SEIA (Solar Energy Industries Association) (2021, June 15). State Solar Spotlights-California. https://www.seia.org/sites/default/files/2021-06/California.pdf

Southern California Edison (2021). Energy Data: Reports and Compliance. https://www.sce.com/regulatory/energy-data---reports-and-compliances

TimeandDate.com (2020). Past Weather in Orange: California. https://www.timeanddate.com/weather/usa/orange/historic? month=1\&year $=2020$

US Energy Information Administration (2021). Electric Power Monthly. https://www.eia.gov/electricity/monthly/epm_table_grapher.php?t=epmt_5_6_a

Zillow (2019, December 18). Zillow Home Value Index Methodology, 2019 Revision: What's Changed \& Why.

https://www.zillow.com/research/zhvi-methodology-2019-highlights-26221/ 